\title{
Analysis of Packed Bed Adsorption Column with Low Cost Adsorbent for Cadmium Removal
}

\author{
Sunil J. Kulkarni*, ${ }^{*}$, Jayant P. Kaware ${ }^{b}$ \\ ${ }^{a}$ Department of Chemical Engineering, Datta Meghe College of Engineering, Airoli, Navi Mumbai, India \\ ${ }^{b}$ Bhonsala College of Engineering and Research, Akola, Maharashtra, India
}

\begin{abstract}
In the current research, removal of cadmium from the effluent by using rice husk adsorbent is studied in packed bed with respect to various parameters like initial concentration, adsorbent dose, bed height and $\mathrm{pH}$. Also the solute uptake data was analyzed for first and second order kinetic equations by varying these parameters. The effect of these parameters on kinetics of solute uptake is reported. It was observed that with increase in initial concentration from $10 \mathrm{mg} / \mathrm{l}$ to $50 \mathrm{mg} / \mathrm{l}$, the exhaustion time decreased from $830 \mathrm{mg} / \mathrm{l}$ to $570 \mathrm{mg} / \mathrm{l}$ and break point time decreased from 330 minutes to 120 minutes. Also with increase in flow rate, exhaust time and break through time decreased significantly. The alkaline conditions favoured the adsorption with optimum $\mathrm{pH}$ of 6.The exhaustion and break through delayed with increasing bed height. The kinetics of the cadmium removal was affected by initial concentration and flow rate. At low initial concentration, it indicated second order kinetics. There was increasing shift from second to first order with increase in initial concentration. With increase in bed height from 30 to $40 \mathrm{~cm}$ there was shift from second to first order but with further increase in bed height, again shift towards second order kinetics was observed. The optimum bed height, initial concentration, flow rate and $\mathrm{pH}$ values were $50 \mathrm{~cm}, 30 \mathrm{mg} / \mathrm{l}, 60 \mathrm{ml} / \mathrm{min}$ and 6 respectively. The adsorption efficiency was estimated to be 69 percent for optimum values of $\mathrm{pH}$, initial concentration, bed height and flow rate.
\end{abstract}

Keywords: adsorbent, break through point, concentration, kinetics.

\section{Introduction}

Removal of heavy metals from the effluent is very important area of research. Smelting, metal plating, batteries, alloy industries, phosphate fertilizers are few industries, having cadmium as the major pollutant. Possible health effects because of cadmium include renal damage, anemia, hyper tension and liver damage. The methods like electrolytic methods, ion exchange methods, chemical methods and immobilization by algae, use of membranes, catholic reduction and adsorption are employed for cadmium removal from water. Adsorption for wastewater treatment is low cost process with advantages like simplicity, low initial capital, possible regeneration of adsorbent and flexibility in terms of equipment

${ }^{*}$ Corresponding author. Tel.: +919664213953

E-mail: suniljayantkulkarni@gmail.com

(c) 2015 International Association for Sharing Knowledge and Sustainability

DOI: $10.5383 /$ ijtee.09.01.003 and method of operation. The removal of cadmium by adsorption has been investigated by number of investigators. The research on removal of cadmium (II) by using various wastes as adsorbents by carried out by Garg et.al.[1]. They used sugarcane bagasse (SCB), maize corncob (MCC) and jatropha oil cake (JOC) as adsorbents. It was observed that, for the adsorbent dose of $20 \mathrm{~g} / \mathrm{l}$, the contact time of 60 minutes was optimum. At the optimum conditions the percentage removal for jatropha oil cake, maize corncob (MCC) and sugarcane bagasse (SCB) was observed to be $99.5 \%, 99 \%$ and $85 \%$ respectively. Mahvi et.al have carried out cadmium removal from the wastewater by using rice husk and its ash[2]. Their research indicated that the cadmium removal efficiency increased with increase in the $\mathrm{pH}$ value up to $\mathrm{pH}$ of 6.The maximum adsorption was observed to be 97.2 and 99.2 percent for rice husk and rice husk ash. It was concluded that rice husk ash was a better adsorbent than rice husk. Srivastava et.al. used 
rice husk ash from rice husk fired furnaces as an adsorbent for cadmium and zinc[3]. The optimum $\mathrm{pH}$ was 6 . With the increase in other metal concentration the uptake of the metal ion decreased. This may be because of consumption of active site by other metal ions. The removal of heavy metal in fixed bed was investigated with respect to solute uptake, affecting parameters and modeling by various researchers. The fixed bed column for lead removal by natural zeolite was studied by Medvidovic et.al[4].Prediction of breakthrough curves for the fixed bed column was done based on a batch experiment. It was found that the mass transfer model was applicable for prediction of the break- through curve from batch experiments. Nwabanne and Igbokwe carried out studies on the adsorption of lead (II) and copper (II) in a fixed bed column using activated carbon prepared from palm nut[5]. Various models were used to explain the solute uptake. It was observed that the rate constant for Thomas model increased with increase in flow rate and initial ion concentration but remained constant at varying bed height. Also the maximum adsorption capacity increased with increase in flow rate and initial ion concentration but decreased with increase in bed height. Tamarind seeds adsorbent for removal of metals in a fixed bed were used by Suganthi [6]. The removal of copper and cadmium in a fixed bed was studied by him. It was observed that breakthrough capacities using wastewater containing cadmium and copper ions for phosphorylated tamarind seed carbon was superior to commercial activated carbon in the removal of metal ions. Muhamad et.al. used wheat straw as an adsorbent for cadmium removal in fixed and batch experiments[7]. They used continuous up flow fixed bed contactor. Investigation was done in the flow rate range of 0.3 to $1 \mathrm{lpm}$ and varying bed height from 0.5 to 2 meter. The results obtained agreed to the bed depth service time (BDST) model. Biosorption of $\mathrm{Pb}$ (II), $\mathrm{Cd}$ (II), and $\mathrm{Hg}$ (II) from simulated aqueous solutions using baker's yeast biomass was investigated by Sulaymon et.al[8]. It was observed that the Cd (II), $\mathrm{Pb}$ (II), and $\mathrm{Hg}$ (II) uptake process followed the pseudosecond order rate model with $\mathrm{R}^{2}$ values $0.963,0.979$, and 0.960 respectively. They used a two parameters model for the modeling of breakthrough curves. It was observed that an increase in the initial concentration of each adsorbate makes the breakthrough curves much steeper. Salmani et al. carried out comparative study of copper (II) removal on iron oxide, aluminum oxide and activated carbon by continuous down flow method[9].The data for experimental breakthrough curves was drawn from the adsorption data of packed bed columns. It was observed that uptake capacity of $\mathrm{Cu}$ (II) was highest for activated carbon $(16.24 \mathrm{mg} / \mathrm{g})$ followed by aluminum oxide $(5.60 \mathrm{mg} / \mathrm{g})$ and iron oxide $(5.41 \mathrm{mg} / \mathrm{g})$. It was found that the Thomas model was in good agreement with experimental capacities determined by adsorption data.

Velizar et.al. used saw dust for heavy metal removal from mine waste[10]. They presented the results on the batch and column adsorption of copper and some associated ions by employing linden and poplar sawdust as a low-cost adsorbent. It was observed that the adsorbent was satisfactory for copper removal with highest adsorption of 80 percent. The results obtained in the batch mode through the column test were verified by using the real mine water originating from an acid mine drainage (AMD) of the copper mine. The results were in agreement with each other. The removal of cadmium in the fixed bed was studied by Long and Dang with modified peanut shells by using potassium permanganate[11]. It was observed that with increase in the bed height, the height of mass transfer zone remained unchanged, whereas it increased with initial concentration and influent flow rates. Cashew nut shell activated carbon was used by Kumar et.al. for removal of cadmium from waste water[12]. It was observed that the acidic conditions favored the removal and the equilibrium time was 30 minutes. The solute uptake followed pseudo-second order equation. The nano zerovalent iron particles were used by Boparai et. al. for cadmium removal[13]. It was observed that the adsorption in this case increases with the increase in temperature as with endothermic reactions. Also the process was second order. Freundlich and Temkin isotherms fitted the adsorption process. Corn stalk was modified using graft copolymerization to produce absorbent for cadmium by Zeng et. al[14].Removal of cadmium from wastewater using emulsion liquid membrane (ELM) was studied by Mohrateb et. al.[15]. The comparative studies of the abilities of four lowcost materials were carried out by Benaissa et.al.[16] The cadmium removing capacity of a biosorbent Calotropis procera, a perennial wild plant was found to be 40 to 50 $\mathrm{mg} / \mathrm{gram}$ by Pandey et al[17]. An agricultural waste-orange peel powder (OPP) was successfully modified into a novel magnetic nano-adsorbent (MNP-OPP) by co-precipitating it with $\mathrm{Fe}_{3} \mathrm{O}_{4}$ nanoparticles (MNP) for cadmium ion removal from aqueous solutions by Gupta and Nayak [18].

The down flow fixed adsorber offer advantage of simple operation plus ability to serve as a filter for simultaneous suspended solid removal. The flow can be operated by gravity. These adsorbers can be arranged in single, multistage or parallel operations. The disadvantage being inability to handle high suspended solids. The removal of cadmium by using down flow fixed bed is investigated in the present research. Also the effect of the parameters like initial concentration, flow rate, $\mathrm{pH}$ and bed depth on the out let concentration is studied. Also the data was analyzed $\mathrm{f}$ or first and second order rate models. The low cost adsorbent obtained from rice husk was used.

\section{Methodology}

The rice husks were obtained from the rice mills in the Konkan area, near Mumbai. The rice husks were dried by heating to $150{ }^{\circ} \mathrm{C}$, till it turns black. Then it was treated with 0.1 molar hydrochloric acid and then with 0.1 normal sodium hydroxide. It was then washed with distilled water and subjected to high temperature $\left(450{ }^{\circ} \mathrm{C}\right)$ for 5-6 hours.. The adsorbent thus obtained was screened to remove extremely small particles below -72 mesh size. The synthetic effluent was prepared by 
using cadmium sulphate. For fixed bed operation, an acrylic column of $5.3 \mathrm{~cm}$ diameter and $100 \mathrm{~cm}$ length was used. The column was fixed with a stand. The adsorbent and sand was mixed with 3:2 volume and packed in the bed. The sand filter was prepared at the bottom of the column. The effluent from the tank above the column was allowed to flow by gravity through the column via distributor. The flow was controlled by needle valve. The treated effluent was collected at the bottom and analyzed. The $\mathrm{pH}$ adjustment, if required was done with $0.1 \mathrm{M}$ hydrochloric acid and $0.1 \mathrm{~N}$ sodium hydroxide. The studies were carried out by using different flow rates, initial concentration, $\mathrm{pH}$ and bed height. Cadmium concentration in the effluent was analyzed by spectrophotometric method.

\section{Results and Discussion}

\subsection{Effect of various parameters on breakthrough curve}

\subsubsection{Effect of initial concentration}

Experiments were carried out with different initial concentrations and $\mathrm{C} / \mathrm{C}_{\mathrm{o}}$ values were plotted against time. $\mathrm{C}$ is concentration at any time $t$ and $\mathrm{C}_{\mathrm{o}}$, the initial concentration at $\mathrm{t}$ $=0$, when the effluent just starts from the bed. The exhaustion time decreased with initial concentration. For the initial concentrations of $10 \mathrm{mg} / \mathrm{l}, 30 \mathrm{mg} / \mathrm{l}$ and $50 \mathrm{mg} / \mathrm{l}$, the exhaustion time was 830, 660 and 570 minutes respectively. The break through time decreased with increase in initial concentration from $10 \mathrm{mg} / \mathrm{l}$ to $50 \mathrm{mg} / \mathrm{l}$. It was 330,270 and 120 respectively at initial concentrations of $10 \mathrm{mg} / \mathrm{l}, 30 \mathrm{mg} / \mathrm{l}$ and $50 \mathrm{mg} / \mathrm{l}$.

\subsubsection{Effect of flow rate}

With increase in flow rate, the time required to reach the exhaustion decreased because of rapid availability of adsorbate. As shown in fig.2, at fixed initial concentration and bed depth, for the flow rates of $10 \mathrm{ml} / \mathrm{min}, 30 \mathrm{ml} / \mathrm{min} 60 \mathrm{ml} / \mathrm{min}$ and 90 $\mathrm{ml} / \mathrm{min}$, the exhaustion time was 660,570 and 540 and 540 minutes respectively. The final, $\mathrm{C} / \mathrm{C}_{\mathrm{o}}$ value at exhaustion decreased with increasing flow rate. This can be because of the fact with increasing flow rate, the residence time for the adsorbate decreases. Considering this, the flow rate of 60 $\mathrm{ml} / \mathrm{min}$. is adequate for the column. Break through time decreased with increase in flow rate and it was 330, 270,240 and 210 minutes respectively at the initial flow rates of 10 , 30,60 and $90 \mathrm{ml} / \mathrm{min}$ respectively.

\subsubsection{Effect of $\mathrm{pH}$}

At higher $\mathrm{pH}$ the existence of $\mathrm{OH}^{-}$ions affect the adsorption adversely. $\mathrm{pH}$ value of 6 is optimum for the adsorption. The effect of $\mathrm{pH}$ is indicated in fig.3.

\subsubsection{Effect of bed height}

As shown in fig.4, the bed heights of $30 \mathrm{~cm}$ and $40 \mathrm{~cm}$ are not sufficient as $C / C_{0}$ values reached are not satisfactory. The time for exhaustion increases with bed height. With increase in bed height, the $\mathrm{C} / \mathrm{C}_{\mathrm{o}}$ value at exhaustion increases, up to the bed height of $50 \mathrm{~cm}$. With further increase in bed height, no significant change is observed. Bed height of $50 \mathrm{~cm}$ is appropriate for the operation.

\subsection{Kinetics of solute uptake}

The effect of various parameters like initial concentration, the flow rate and bed height on the kinetics of solute uptake is studied. Ordinary first and second order models were tested for the data obtained. For first order model C.C $\mathrm{C}_{0}$ on logarithmic scale was plotted against time and for second order model 1/C $1 / C_{0}$ was plotted against time.

\subsubsection{Effect of initial concentration on solute uptake kinetics} At low concentrations of solute, the adsorption followed second order kinetics. As shown in fig. 5 to 7, the solute uptake becomes increasingly first order in nature with increase in initial concentration from $10 \mathrm{mg} / \mathrm{l}$ to $50 \mathrm{mg} / \mathrm{l}$. The adsorption depends on both, the solute concentration and available adsorbent sites, at low initial concentration, following second order model. While at higher solute concentration it becomes less dependent on solute concentration, indicating first order kinetics. At higher initial concentration, the adsorption uptake followed second order kinetics also up to initial concentration of $40 \mathrm{mg} / \mathrm{l}$.

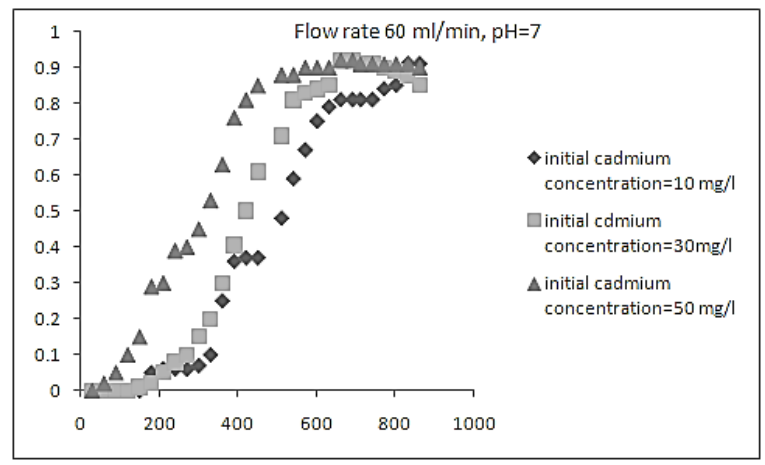

Fig.1:C/Co verses time in minutes at various initial concentrations

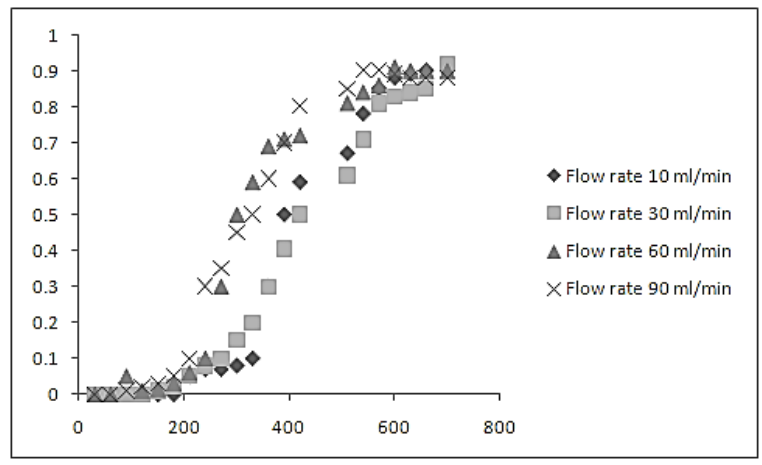

Fig.2: $\mathrm{C} / \mathrm{Co}$ verses time in minutes at various flow rates

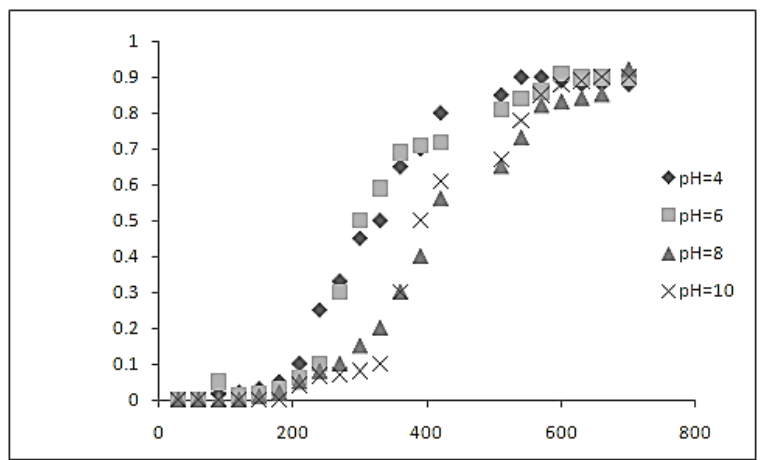

Fig.3: $\mathrm{C} / \mathrm{Co}$ verses time in minutes at various $\mathrm{pH}$ values 


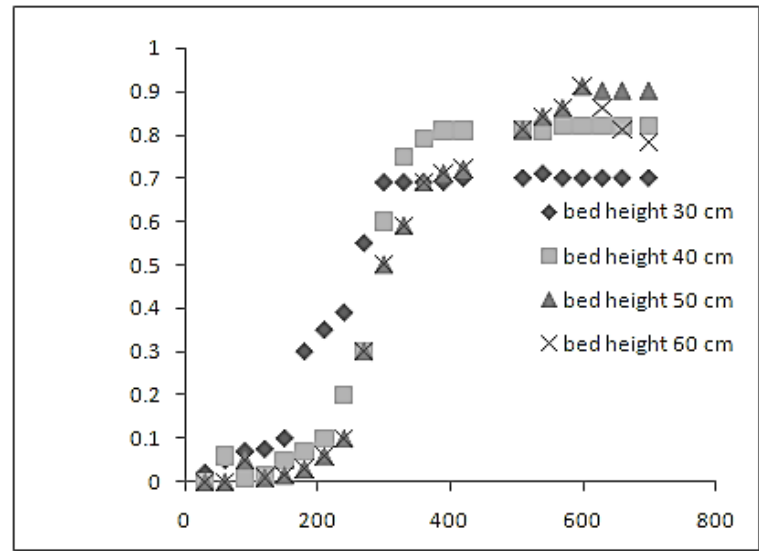

Fig.4: $\mathrm{C} / \mathrm{Co}$ verses time at various bed heights

\subsubsection{Effect of flow rate on solute uptake kinetics}

Effect of flow rate was studied by keeping all other parameters constant. It is shown in fig. 8 to 11 . At lower flow rate the kinetics was second order. For the maximum flow rate of 90 $\mathrm{ml} / \mathrm{min}$, the solute uptake was first order in nature. For the intermediate flow rates of 30 and $60 \mathrm{ml} / \mathrm{min}$, there was shift from second order to first order. At these concentrations, first order kinetics was observed, thought the adsorption also followed second order equation reasonably well. The increase in flow rate allows more solute ions to come in contact with adsorbent, hence it becomes less dependent on the availability of adsorbate, indicating first order kinetic behavior.

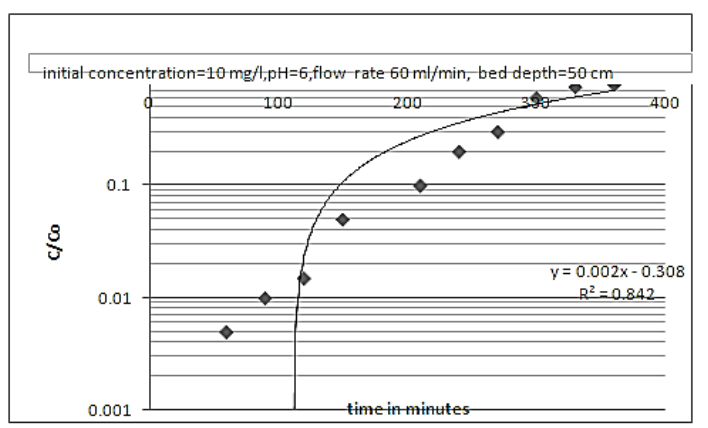

Fig 5a: First order kinetics, initial concentration $10 \mathrm{mg} / \mathrm{l}$

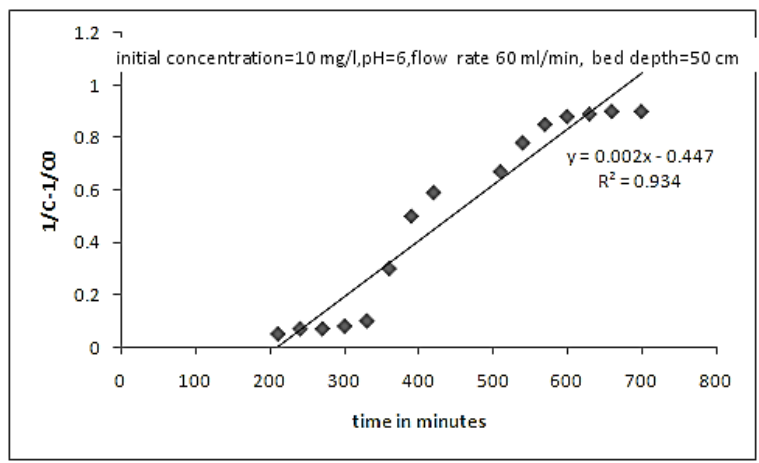

Fig 5b: Second order kinetics, initial concentration $10 \mathrm{mg} / \mathrm{l}$

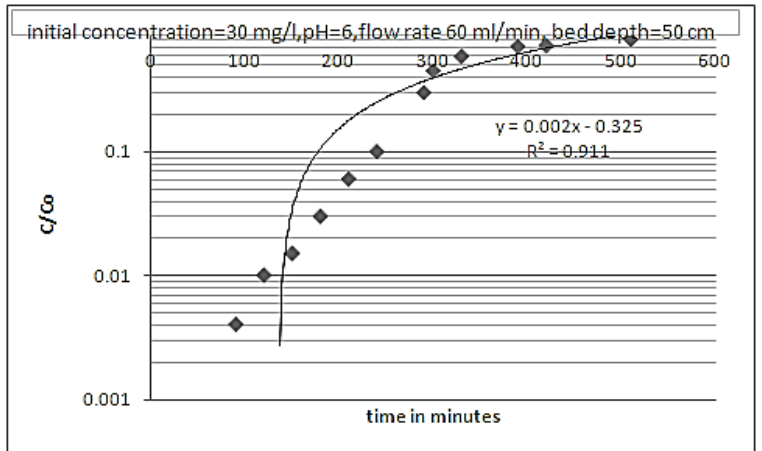

Fig 6a: First order kinetics, initial concentration $30 \mathrm{mg} / \mathrm{l}$

\subsubsection{Effect of bed height on solute uptake kinetics}

Effect of bed height on solute uptake kinetics is presented in fig. 12 to 15 . All the parameters other than bed depth were kept constant. Fig.12 depicts the effect of initial concentration for bed depth of $30 \mathrm{~cm}$. The solute uptake kinetics fitted second order equation better with $\mathrm{R}^{2}$ value of 0.906 as against first order with $\mathrm{R}^{2}$ value of 0.878 . This may be because the adsorbent requirement and insufficient adsorbent contact. With increase in bed depth from 30 to $40 \mathrm{~cm}$ the solute uptake kinetics followed first order model better, with $\mathrm{R}^{2}$ value of 0.937 , thought second order model also described the kinetics satisfactorily. For bed heights of 50 and $60 \mathrm{~cm}$, the second order kinetics was followed by solute uptake with $\mathrm{R}^{2}$ values above 0.95 . For these heights, the first order model was not satisfactory with $\mathrm{R}^{2}$ values of 0.84 to 0.87 .It indicated that at bed depths of 50 and $60 \mathrm{~cm}$, though more adsorbent was available, the rate of adsorbent also depends on solute concentration, which was kept constant.

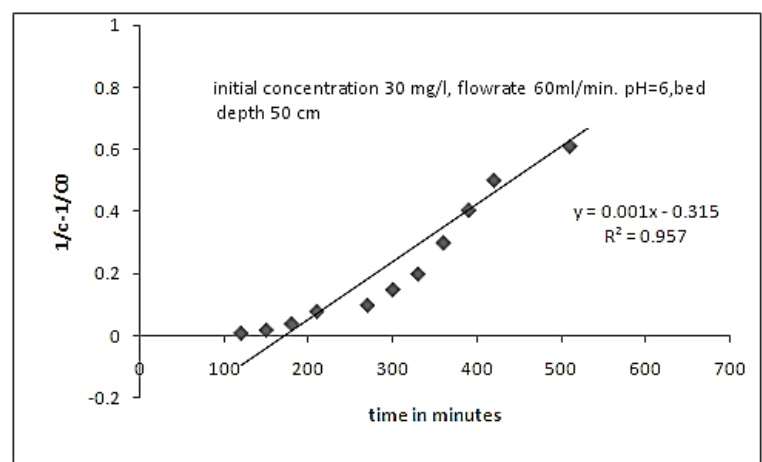

Fig 6 b: Second order kinetics, initial concentration $30 \mathrm{mg} / \mathrm{l}$

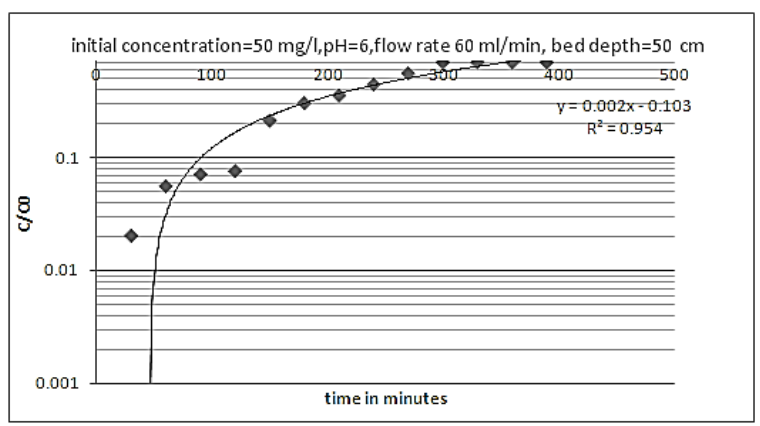

Fig 7a: First order kinetics, initial concentration 50 mg/l 


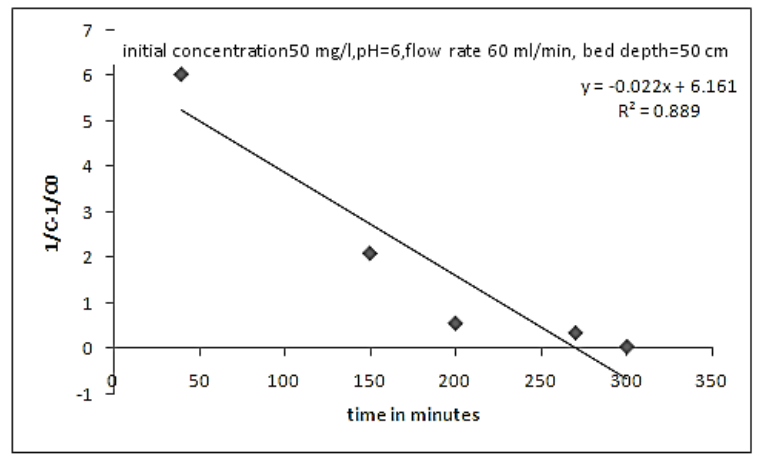

Fig.7b: Second order kinetics, initial concentration $50 \mathrm{mg} / \mathrm{l}$

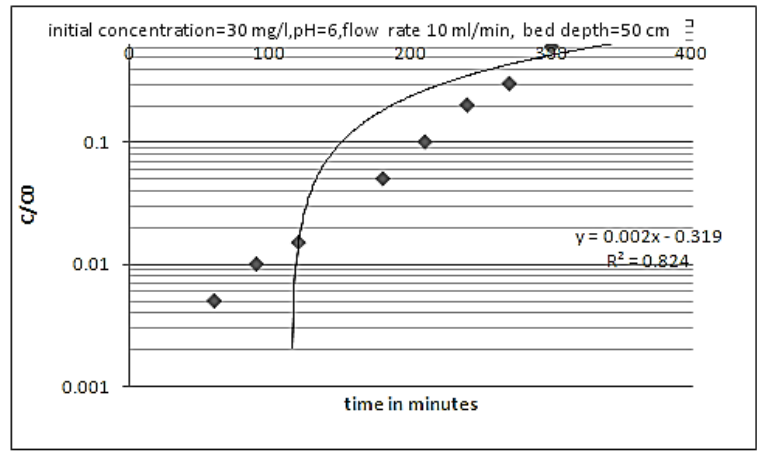

Fig. 8a: First order kinetics, flow rate $10 \mathrm{ml} / \mathrm{min}$

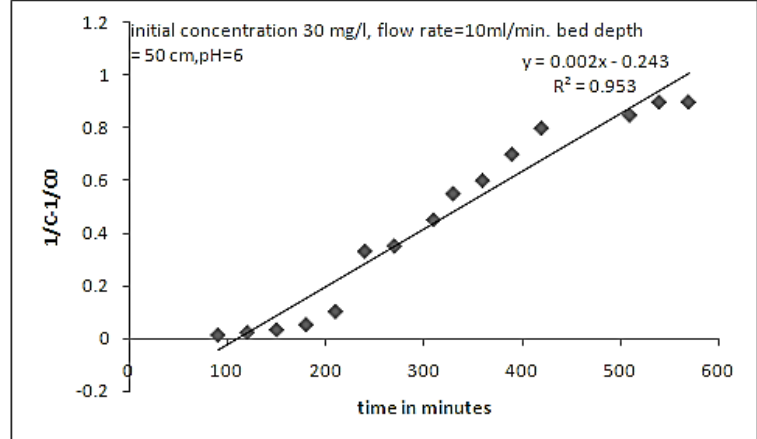

Fig. 8b: Second order kinetics, flow rate $10 \mathrm{ml} / \mathrm{min}$

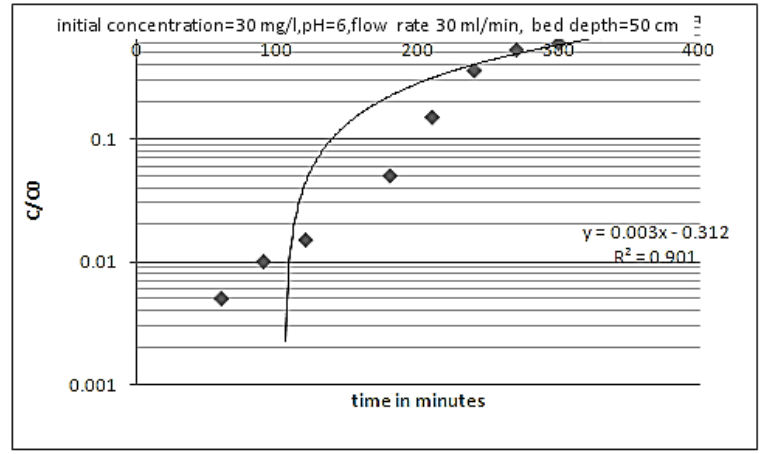

Fig. 9a: First order kinetics, flow rate $30 \mathrm{ml} / \mathrm{min}$



Fig 9b: Second order kinetics, flow rate $30 \mathrm{ml} / \mathrm{min}$

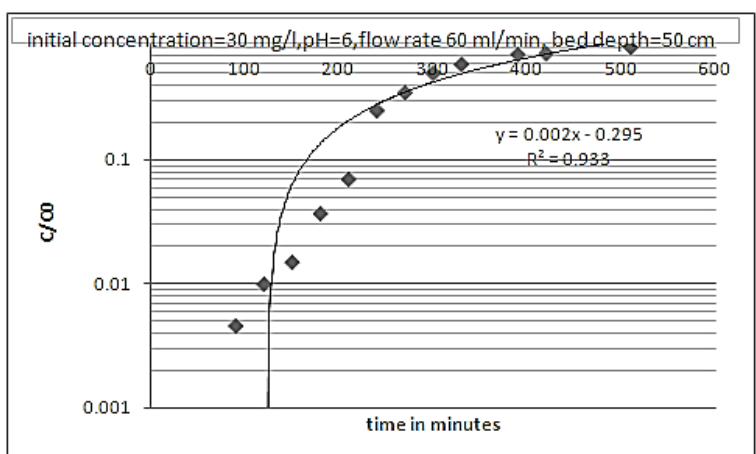

Fig. 10 a: First order kinetics, flow rate $60 \mathrm{ml} / \mathrm{min}$

3.3.Fixed bed efficiency, exhaustion rate retention time The total amount of cadmium adsorbed is calculated by plotting adsorbed concentration verses time up to exhaustion. The area under the curve when multiplied by flow rate gives the amount adsorbed. These calculations were done for optimum values of flow rate, initial concentration and bed depth. These values were $60 \mathrm{ml} / \mathrm{min}, 30 \mathrm{mg} / \mathrm{l}$ and $50 \mathrm{~cm}$ respectively. The corresponding amount of cadmium removed was found to be $870 \mathrm{mgs}$. The amount of adsorbent fed was calculated by using flow rate and the exhaustion time. The amount of cadmium treated was $1260 \mathrm{mg}$. The removal efficiency was 69 percent in the column. The total empty bed retention time was 16.35 minutes. Time equivalent to stoichiometric capacity was 483.3 minutes. The adsorbent exhaustion rate was found to be 2.7 grams per $\mathrm{ml}$. The fraction of unused bed length was 0.78 . The following equations were used for these computations.

$q_{t}=Q / 1000 \int C_{a d} \cdot d t$

EBRT $=$ bed volume $/$ volumetric flow rate

Length of unused bed $=1-\frac{t_{b}}{t_{t}}$ 


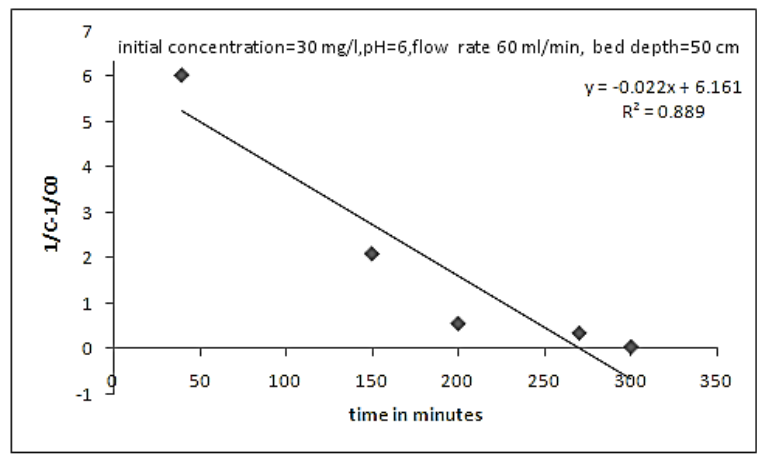

Fig. $10 \mathrm{~b}$ :Second order kinetics, flow rate $60 \mathrm{ml} / \mathrm{min}$

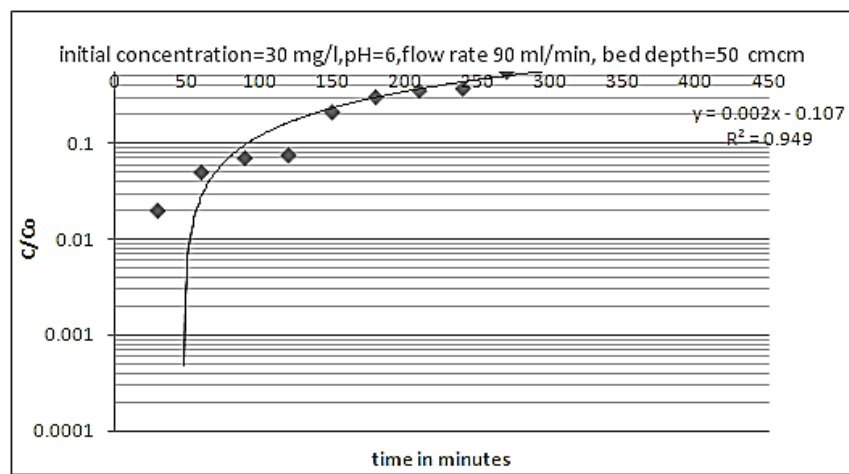

Fig. 11 a:First order kinetics, flow rate $90 \mathrm{ml} / \mathrm{min}$

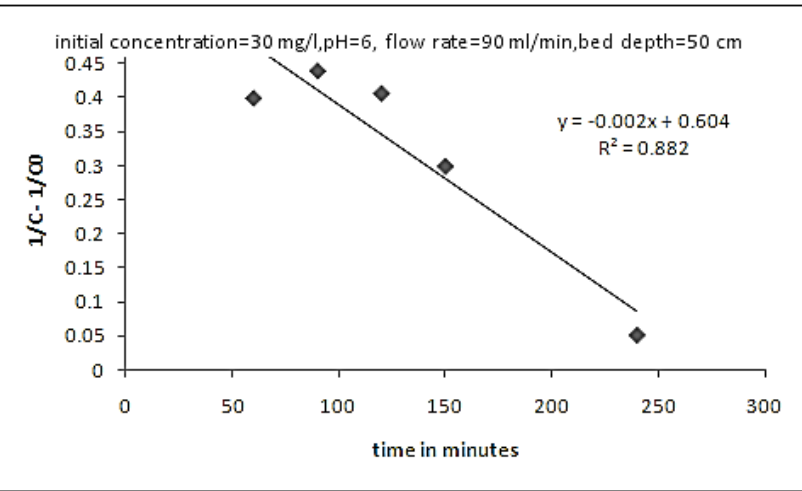

Fig. 11 b:Second order kinetics, flow rate $90 \mathrm{ml} / \mathrm{min}$

$\mathrm{q}_{\mathrm{t}}$ is the mass adsorbed at time $\mathrm{t}(\mathrm{mg}), \mathrm{Q}$, the flow rate $(\mathrm{ml} / \mathrm{min})$ of influent, $\mathrm{C}_{\mathrm{ad}}$, the adsorbed concentration $(\mathrm{mg} / \mathrm{l}), \mathrm{t}_{\mathrm{b}}$, the break through time(minutes), $\mathrm{t}_{\mathrm{t}}$, the total time till exhaustion(minutes).

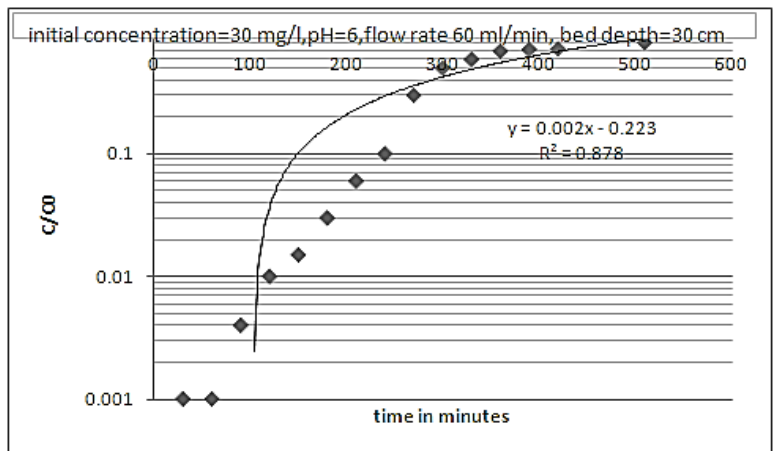

Fig12a.: First order kinetics, bed height $30 \mathrm{~cm}$

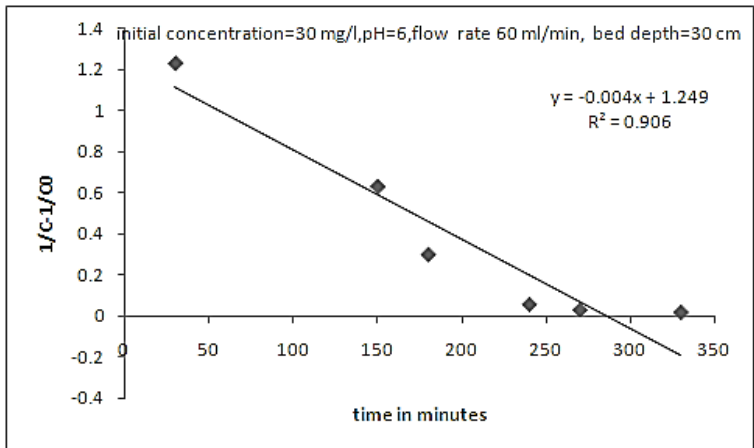

Fig12b.: Second order kinetics, bed height $30 \mathrm{~cm}$

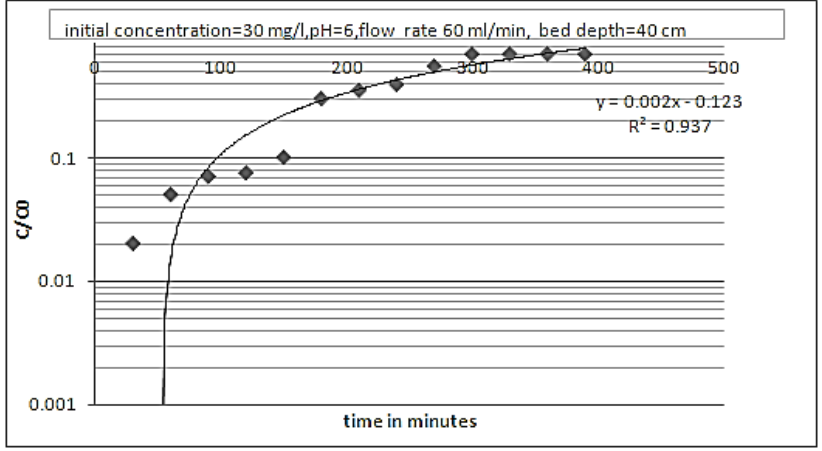

Fig.13a: First order kinetics, bed height $40 \mathrm{~cm}$

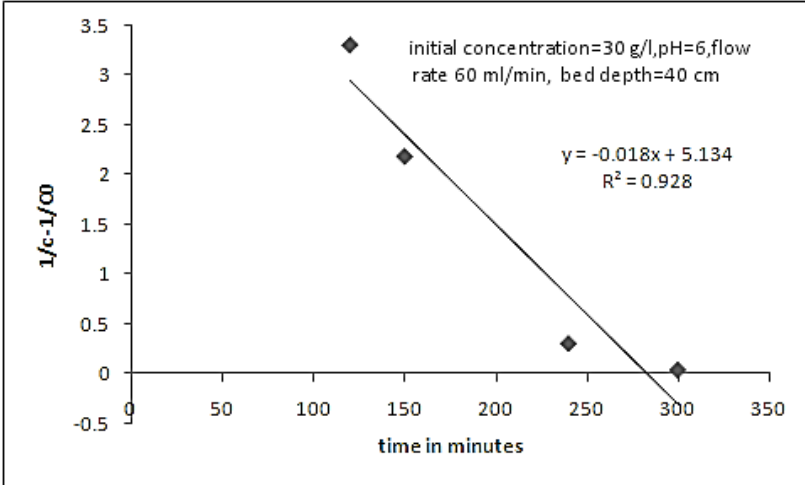

Fig.13b.: Second order kinetics, bed height $40 \mathrm{~cm}$

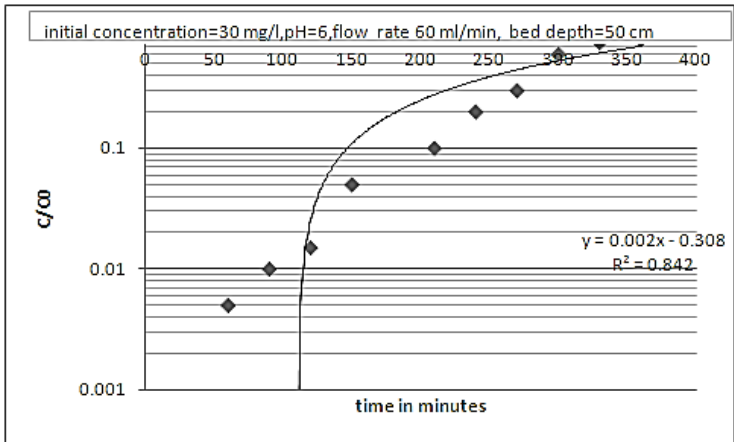

Fig14a.: First order kinetics, bed height $50 \mathrm{~cm}$ 


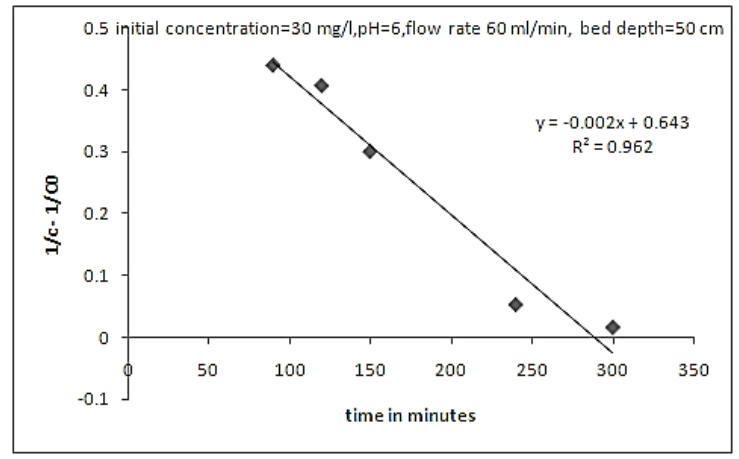

Fig14b.: Second order kinetics, bed height $50 \mathrm{~cm}$

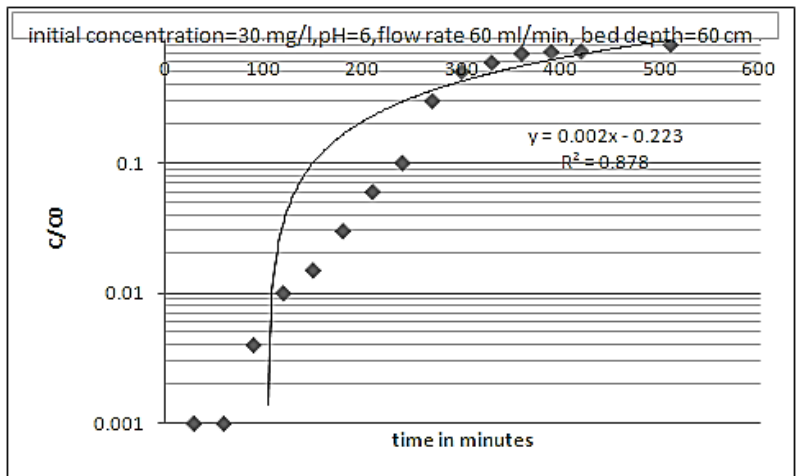

Fig. 15a: First order kinetics, bed height $60 \mathrm{~cm}$

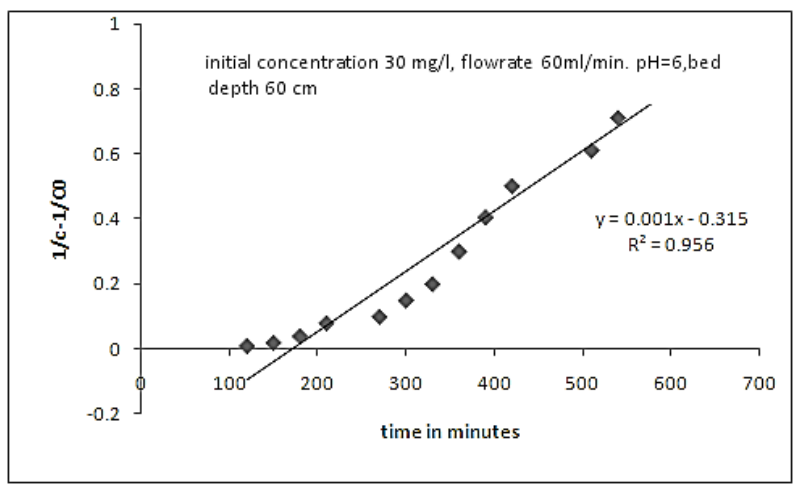

Fig. 15b: Second order kinetics, bed height $60 \mathrm{~cm}$

\section{Conclusion}

Fixed bed adsorption was found to be efficient method for cadmium removal. The adsorption efficiency of the bed was estimated to be 69 percent. Alkaline conditions favored the adsorption. The parameters like bed depth, initial concentration and the flow rate affect the nature of breakthrough curve, break through time and exhaustion time. With increase in initial concentration and flow rates, the exhaustion time and break through time decreased. While with increase in the bed height, the break through and exhaustion time delayed. There was shift from second to first order with increase in initial concentration.

\section{References}

[1] Garg U, Kaur MP, Jawa GK, Sud D, Garg V.K.,Removal of cadmium (II) from aqueous solutions by adsorption on agricultural waste biomass, Journal of Hazards Mater,2008; 154(1-3)1149-57.
[2] Mahvi A.H., Alavi N. and Maleki A., Application of Rice Husk and its Ash in Cadmium Removal from Aqueous Solution, Pakistan J Biological Science, 2005;8(5)721-725.

[3] Srivastava V.C., Mall I.D., Mishra I.M.,Equilibrium modelling of single and binary adsorption of cadmium and nickel onto bagasse fly ash, Chemical Engineering Journal,2006,117(1),79-91..

[4] N. Vukojevic Medvidovic, J. Peri' c, M. Trgo,Column performance in lead removal from aqueous solutions by fixed bed of natural zeolite-clinoptilolite, Separation and Purification Technology,2006;49,237-244..

[5] Nwabanne, J. T and Igbokwe, P. K.,Kinetic Modeling of Heavy Metals Adsorption on fixed bed Column, Int. J. Environ. Res., 2012;6(4),945-952.

[6] N. Suganthi,Fixed Bed Column Adsorption Studies for Removal of Metal Ions using Tamarind Seeds, Coromandal Journal of Science,2012, 1(1),65-71.

[7] H. Muhamad, H. Doan, A. Lohi, Batch And Fixed-Bed Column Biosorption Of $\mathrm{Cd}^{2+}$ and $\mathrm{Cu}^{2+}$ Onto Wheat Straw, Chemical Engineering Journal,2010,158(3),369377.

[8] Abbas H. Sulaymon, Shahlaa E. Ebrahim, Tariq J. Al Musawi ,Sama M. Abdullah, Removal of Lead, Cadmium, and Mercury Ions Using Biosorption, Iraqi Journal of Chemical and Petroleum Engineering,2010, 1(2)1-13.

[9] Mohammad Hossein Salmani, Mahmoud Vakili and Mohammad Hassan Ehrampoush, A comparative study of copper (ii) removal on iron oxide, aluminum oxide and activated carbon by continuous down flow method,Journal of Toxicology and Environmental Health Sciences, 2013,5(8),150-155.

[10] Stankovic Velizar, Bozic Dragana, Gorgievski Milan, Bogdanovic G., Heavy Metal Ions Adsorption From Mine Waters By Sawdust ,Chemical Industry And Chemical Engineering,2009,14(4),237-249.

[11] Long T, Yi XY, Dang Z, Dynamic adsorption of cadmium (II) in water on modified peanut shells, Huan Jing $\mathrm{Ke}$ Xue,2012, 33(9),3177-81.

[12] Kumar P.S.,SubramaniamR.,Vasanthakumar S.,Selvaraj D. K., Arukkani M.,Subramanian S., Removal of cadmium(II) from aqueous solution by agricultural waste cashew nut shell, Korean J Chemical Engineering,2012,29(.6),756-768.

[13] Boparai H.K., Meera J.,Carroll D.O.,Kinetics and thermodynamics of cadmium ion removal by adsorption onto nano zerovalent iron particles, ,J Hazardous Mater,2011,186(1),458-65.

[14] Liuchun Zheng, Zhi Dang ' Chaofei Zhu, Xiaoyun Yi Hui Zhang, Congqiang Liu, Removal of cadmium(II) from 
aqueous solution by corn stalk graft copolymers, Bioresource Technology, 2010,101(15)5820-5826.

[15] Hamid R. Mortaheb, Hitoshi Kosuge, Babak Mokhtarani, Mohammad H. Amini, Hamid R. Banihashemi,Study on removal of cadmium from wastewater by emulsion liquid membrane, Journal of Hazardous Materials;2009, 165(13) 630-636.

[16] H. Benaissa, M. Meziani, And E.A.Elouchdi, Screening of new sorbent materials for cadmium removal from aqueous solution", Proceedings of Eighth International Water
Technology Conference, IWTC8, Alexandria,2004, Egypt,279 -288.

[17] Piyush Kant Pandey, Yashu Verma, Shweta Choubey, Madhurima Pandey, K. Chandrasekhar, biosorptive removal of cadmium from contaminated groundwater and industrial effluents, Bioresource Technology,2008,99(10),4420-4427.

[18] V.K. Gupta,Arunima Nayak,2012, "Cadmium removal and recovery from aqueous solutions by novel adsorbents prepared from orange peel and $\mathrm{Fe}_{2} \mathrm{O}_{3}$ nanoparticles", Chemical Engineering Journal,2012,180(15), 1-90. 